\section{International Scientific Journal Theoretical \& Applied Science}

p-ISSN: 2308-4944 (print) ｅ-ISSN: 2409-0085 (online)

Year: $2016 \quad$ Issue: 2 Volume: 34

Published: 29.02.2016 http://T-Science.org
Vasila Karimbekovna Abdullaeva associate professor, candidate of medical sciences, head of department

Tashkent pediatric medical institute, Uzbekistan vasila.abdullaeva@tashpmi.uz

\title{
THE INTENSITY OF SYSTEMIC OXIDATIVE STRESS AND OPTIMIZATION OF THERAPEUTIC TACTICS IN PATIENTS WITH OPIOID DEPENDENCE
}

Abstract: Investigated the pathogenetic significance of systematic oxidative stress, depending on the duration of narcotization of opioids and availability of associated liver damage and further optimization of therapeutic tactics.

Key words: opioid addiction, oxidative stress, optimization of therapeutic tactics.

Language: Russian

Citation: Abdullaeva VK (2016) THE INTENSITY OF SYSTEMIC OXIDATIVE STRESS AND OPTIMIZATION OF THERAPEUTIC TACTICS IN PATIENTS WITH OPIOID DEPENDENCE. ISJ Theoretical \& Applied Science, 02 (34): 66-71.

Soi: http://s-o-i.org/1.1/TAS-02-34-11 Doi: crossef http://dx.doi.org/10.15863/TAS.2016.02.34.11

\section{ИНТЕНСИВНОСТЬ СИСТЕМНОГО ОКИСЛИТЕЛЬНОГО СТРЕССА И ОПТИМИЗАЦИЯ ТЕРАПЕВТИЧЕСКОЙ ТАКТИКИ У БОЛЬНЫХ С ЗАВИСИМОСТЬЮ ОТ ОПИОИДОВ}

Аннотация: Изучено патогенетическое значение системного окислительного стресса в зависимости от длительности наркотизации опиоидами и наличия сопутствующего поражения печени с последующей оптимизацией терапевтической тактики.

Ключевые слова: зависимость от опиоидов, окислительный стресс, терапевтическая тактика.

В последнее время все большее внимание уделяется участию патохимических реакций в генезе многих заболеваний [2, с.60; 7, с.61]. Исследования доказали, что наркотическая зависимость сопровождается увеличением сердечно-сосудистой заболеваемости, поражений печени, почек, дыхательной системы [8, с. 54; 10 , c.11]. Изучение состояния печени при героиновой наркомании чрезвычайно важно, т.к. от этого зависит течение абстиненции, ибо обезвреживание и клиренс наркотика осуществляется печенью [9, с.437].

В литературе имеется достаточно сведений, констатирующих активацию свободнорадикального окисления и наличие эндогенной интоксикации при героиновой наркомании, показано усугубление липопероксидации, возрастание уровня оксида азота и перекисного гемолиза эритроцитов при увеличении дозы героина, а также корреляция низкого уровня NO и низкой концентрации в плазме антиоксидантов (витамина Е и С) при длительной наркотизации
$[11$, с. $121 ; 12$, с. 476$]$. Тем не менее, взаимосвязи уровня генерации активных форм кислорода (АФК) и особенностей течения абстинентного синдрома, влияния соматической патологии, не проводилось.

Целью исследования явилось изучение патогенетического значения системного окислительного стресса в зависимости от длительности наркотизации опиоидами и наличия сопутствующего поражения печени с последующей оптимизацией терапевтической тактики.

Материал и методы исследования. В исследование было включено 52 больных мужского пола в возрасте от 18 до 55 лет, имеющих клинически очерченную зависимость от наркотиков опийной группы (МКБ 10 - F11.2). Для проведения анализа значимости клиникодинамических факторов в развитии зависимости от опиоидов обследованные больные разделены нами на 2 группы: 1 группа больных, зависимых от опиоидов, в сочетании с соматическими 
расстройствами, и группа сравнения представлена больными с зависимостью от опиоидов без соматического заболевания. Данные по основным соматическим расстройствам в основной группе исследования: наличие вирусных гепатитов В и С. Основными методами исследования были клиникопсихопатологический, а также стандартизированные психологические методики: шкала патологического влечения к наркотику (Иванец Н.Н., Винникова М.А., 2001). Для определения интенсивности процессов перекисного окисления липидов (ПОЛ) было проведено определение уровня малонового диальдегида (МДА) в сыворотке крови [4], активности каталазы в крови [3], определение среднемолекулярных пептидов (СМП) [2].

Результаты исследования и их обсуждение. В ходе исследования нами выявлено, что уровень ферментемии в общей группе был выше контрольного, однако находился в пределах референс интервала (11-66 Е/л), что указывает на отсутствие острого или хронического поражения печени. Более глубокий анализ полученных данных позволил установить, что интенсивность генерации АФК в крови, а также активность аланинтрансферазы (АЛТ) у обследованных пациентов изменяется в широких пределах и возрастает с увеличением длительности наркотизации, присоединения поражения печени в виде токсикоинфекционного гепатита, что явилось основанием выделить группу пациентов со стажем наркотизации до 1 года $-8,3 \pm 2,1$ мес. и лиц, употребляющих опий более 1 года - 20,2 $\pm 9,8$ мес.

При таком подходе к трактовке полученных данных удалось выявить, что у пациентов с длительностью наркотизации до 1 года имеется умеренно выраженная эндотоксемия (увеличение СМП в 3 раза) и окислительный стресс (увеличение МДА в 2,6 раза) на фоне снижения активности каталазы в 1,5 раза по сравнению с контролем, тогда как у лиц с длительностью наркотизации более 1 года снижение активности каталазы наблюдалось в 3,5 раза, а уровень МДА и СМП превышали контроль в 5,0 и 5,5 раза соответственно (табл.1).

Таблица 1

Генерация активных форм кислорода в крови больных в зависимости от длительности употребления опиоидов.

\begin{tabular}{|c|c|c|c|c|}
\hline Группа больных & $\begin{array}{c}\text { МДА, } \\
\text { нмоль /мг белка }\end{array}$ & $\begin{array}{c}\text { СМП, } \\
\text { УЕ/мг белка }\end{array}$ & $\begin{array}{c}\text { Каталаза, } \\
\text { ммоль } \mathrm{H}_{2} \mathrm{O}_{2} / \\
\text { млн. эрит } *_{\text {мин }}\end{array}$ & АЛТ, Е/л \\
\hline $\begin{array}{ll}\text { Контрольная } & \text { группа } \\
(\mathrm{n}=12) & \end{array}$ & $0,51 \pm 0,09$ & $0,021 \pm 0,001$ & $40,1 \pm 1,7$ & $30,3 \pm 3,9$ \\
\hline $\begin{array}{l}\text { Группа } \\
(\mathrm{n}=52)\end{array}$ & $1,82 \pm 0,72 *$ & $0,089 \pm 0,019^{*}$ & $22,7 \pm 5,9^{*}$ & $53,2 \pm 7,1^{*}$ \\
\hline $\begin{array}{l}\text { Длительность } \\
\text { наркотизации до } 1 \text { года } \\
(\mathrm{n}=21)\end{array}$ & $1,31 \pm 0,10^{*}$ & $0,063 \pm 0,009^{*}$ & $26,9 \pm 1,1^{*}$ & $39,4 \pm 2,7$ \\
\hline $\begin{array}{l}\text { Длительность } \\
\text { наркотизации } \\
\text { года }(\mathrm{n}=31)\end{array}$ & $2,61 \pm 0,13 * *$ & $0,109 \pm 0,012 * *$ & $11,6 \pm 0,9 * *$ & $72,8 \pm 5,1 * *$ \\
\hline
\end{tabular}

Как видно из табл. 1., усиление генерации АФК в крови у больных с зависимостью от опиоидов происходило с увеличением стажа наркотической зависимости и присоединения поражения печени. Различия показателей МДА, СМП, каталазы и АЛТ крови в зависимости от длительности наркотизации во всех случаях были достоверными ( $<<0,05)$.

Активность АЛТ в среднем была повышена относительно контроля в 2,4 и 1,3 раза у лиц с длительностью наркотизации более 1 года и до 1 года, составив $72,8 \pm 5,1$ и $39,4 \pm 2,7$ Е/л соответственно. Отметим, что ферментемия в 2-3 раза, превышающая норму, как правило, не сопровождается клиническими проявлениями, несмотря на наличие синдрома цитолиза [51].

Полученные нами результаты свидетельствуют о влиянии длительности наркотизации и сопутствующего ей поражения печени на степень окислительного стресса в 
крови при зависимости от опиоидов. Поражение печени скудно проявляется клинически, однако о функциональном поражении гепатоцитов свидетельствует системный окислительный стресс, который развивается при исчерпании антиоксидантной мощности организма и депо антиоксидантов в печени.

Как показали наши наблюдения, окислительный стресс сопровождается эндогенной интоксикацией, т.к. взаимодействие АФК с молекулами белковой природы приводит к образованию низкомолекулярных продуктов $(\mathrm{Mr}<5000$ Да), обладающих токсическим действием - СМП-273.

Одним из важнейших неблагоприятных негативных последствий хронической наркотизации опиатами является физическая зависимость, проявляющаяся специфическими поведенческими нарушениями, и как ее следствие - развитие абстинентного синдрома. На течение абстинентного синдрома существенно влияют характерные для синдрома зависимости от опиоидов соматические расстройства гепатотоксичность и иммунодефицит.

Так, согласно нашим данным, в период воздержания от наркотиков у больных при синдроме зависимости от опиоидов были выявлены аффективные, идеаторные, поведенческие и вегетативные компоненты патологического влечения, актуализация которых отличалась вариабельностью, пароксизмальностью или волнообразностью, а характер был прямо противоположен действию опиоидов.

\section{Таким}

образом,

особенностью

биохимических нарушений гомеостаза у больных-наркоманов, употребляющих опиоиды, является развитие усиления генерации АФК в крови, следствием чего является развитие эндотоксемии в виду накопления продуктов деградации макромолекул. Вероятно, столь разительное увеличение изученных параметров явилось следствием недостаточности защитной системы, включающей как ферменты с антипероксидным и антирадикальным механизмом действия, так и резерв жиро- и водорастворимых биоантиоксидантов в печени [179]. Возможно, эндогенная интоксикация и окислительный стресс связаны и с поражением печени, они влияют на течение абстинентного синдрома, т.к. у больных с высоким уровнем МДА и СМП абстиненция протекала длительнее и тяжелее.

Необходимо отметить, что наши результаты исследования состояния антиоксидантной системы у больных, употребляющих опиоиды, свидетельствуют об угнетении ферментативного звена антиоксидантной защиты и необходимости включения препаратов, обладающих антиоксидантными свойствами, при лечении данной категории больных. Купирование окислительного стресса необходимо для нормализации мембранодеструктивных процессов в организме, в первую очередь, в мозге и печени, что обеспечит адекватность метаболизма в микросомальной окислительной системы препаратов, используемых в лечении антидепрессантов, нейролептиков и др., оптимизирует постнаркотическую детоксикацию, что позволит укоротить течение абстинентного синдрома и снизить его тяжесть.

Учитывая выявленные патохимические особенности течения острой и хронической наркотической интоксикации опиатами, а также наличие системного окислительного стресса в крови у лиц, зависимых от опиоидов, традиционная терапевтическая тактика была оптимизирована следующим образом: включена патогенетическая терапия с воздействием на метаболические процессы с использованием антиоксидантов, применены индивидуальные подходы к назначению психотропных средств в рамках существующих стандартов терапии. При купировании опийного абстинентного синдрома использовались психофармакологические препараты согласно протоколу лечения опиоидной зависимости [6], направленные на купирование его основных компонентов: анальгетики (диклофенак), транквилизаторы (сибазон), а также средства, направленные на подавление патологического влечения к наркотику (карбамазепин). К данной схеме в некоторых случаях для купирования патологического влечения к наркотику добавлялся нейролептик. Ограниченное использование нейролептиков у больных с коморбидной патологией было связано с парадоксальными клиническими эффектами за счет усиления психомоторного возбуждения, высокой частотой побочных эффектов с развитием явлений нейролептического синдрома (акатизии), неврологических осложнений. При включении в схему лечения нейролептика его выбор определялся особенностями психопатологического компонента абстинентного синдрома. У больных, зависимых от опиоидов с коморбидной патологией, при проведении терапии абстинентного синдрома в качестве патогенетической терапии вирусных гепатитов проводилась массивная инфузия коллоидных и кристаллоидных растворов, растворов глюкозы с коррекцией электролитного состава крови и кислотно-щелочного равновесия. Адекватная инфузионная терапия приводила к улучшению общего состояния больных и повышала переносимость применяемых при купировании абстинентного синдрома лекарственных средств. Наряду с традиционной в

ISPC Technology and Innovation, 


\section{качестве}

патогенетической мембранопротекторной терапии назначался альфа-токоферол в дозе 800 мг/сут на 2 приема. Также больным с коморбидной патологией в течение всего курса терапии назначались гепатопротекторы. Дозы употребляемых лекарственных средств определялись с учетом биологических факторов: суточная доза употреблявшегося героина, длительность наркотизации, конституция и вес больного. Для снижения риска осложнений и минимизации побочных действий психотропных средств назначались возможно меньшие дозы препаратов в группе больных с коморбидной патологией. На этапе постабстинентных расстройств препаратами выбора были антидепрессанты и нейролептические средства.

В процессе исследования было проведено сравнение эффективности традиционной терапии и оптимизированного лечения с применением антиоксиданта альфа-токоферола. Пробы крови забирали до медикаментозного купирования абстинентного синдрома, а также после прохождения 2-недельной реабилитации. Избыточное образование АФК при абстиненции инициирует процесс перекисное окисление липидов (ПОЛ) в крови пациентов обеих клинических групп (табл. 2), что подтверждается возрастанием уровня МДА в зависимости от длительности наркотизации относительно нормы. Важнейшая роль в регуляции свободнорадиальных процессов принадлежит антиоксидантному ферменту каталазе, который функционирует сопряженно и ингибирует ПОЛ на стадии активации кислорода, зарождения и разветвления цепного процесса.

Таблица 2

Генерация активных форм кислорода в крови в зависимости от длительности употребления опиоидов.

\begin{tabular}{|c|c|c|c|c|c|c|}
\hline Показатели & \multicolumn{2}{|c|}{ МДА, нмоль /мг белка*мин } & \multicolumn{2}{|c|}{ СМП, УЕ/мг белка } & \multicolumn{2}{|c|}{$\begin{array}{c}\text { Каталаза, ммоль } \mathrm{H}_{2} \mathrm{O}_{2} / \\
\text { млн. эрит * мин }\end{array}$} \\
\hline контроль & \multicolumn{2}{|c|}{$0,51 \pm 0,09$} & \multicolumn{2}{|c|}{$0,021 \pm 0,001$} & \multicolumn{2}{|c|}{$40,1 \pm 1,7$} \\
\hline $\begin{array}{l}\text { Длитель-ность } \\
\text { наркоти-зации }\end{array}$ & До 1 года & Более 1 года & До 1 года & Более 1 года & До 1 года & $\begin{array}{c}\text { Более } 1 \\
\text { года }\end{array}$ \\
\hline До лечения & $1,31 \pm 0,10 * *$ & $2,61 \pm 0,13 * *$ & $0,063 \pm 0,009 * *$ & $0,109 \pm 0,010^{* *}$ & $26,9 \pm 1,1 * *$ & $11,6 \pm 0,9 * *$ \\
\hline $\begin{array}{l}\text { Традиционный } \\
\text { метод лечения }\end{array}$ & $1,24 \pm 0,09 * *$ & $2,94 \pm 0,10 * *$ & $0,059 \pm 0,009 * *$ & $0,099 \pm 0,012 * *$ & $24,1 \pm 1,1 * *$ & $12,4 \pm 1,1 * *$ \\
\hline $\begin{array}{l}\text { Оптимизи- } \\
\text { рованный } \\
\text { метод лечения }\end{array}$ & $0,82 \pm 0,10 * * *$ & $1,1,33 \pm 0,10 * * *$ & $0,033 \pm 0,009 * * *$ & $0,045 \pm 0,012 * * *$ & $38,1 \pm 0,9 *$ & $35,8 \pm 2,1 * *$ \\
\hline
\end{tabular}

Примечание. * - достоверно по отночению к традиционному способу лечения, $P<0,05$; ** достоверно относительно контроля, $(P<0,05)$, *** - достоверно относительно до лечения $(P<0,05)$.

Сравнительное обследование двух групп больных наркоманией, получавших различное лечение - традиционное и оптимизированное в сочетании с альфа-токоферолом показывает более выраженный лечебный эффект биорегулируемой антиоксидантной терапии. При традиционном способе лечения больных, уровень МДА был достоверно выше показателя до лечения в подгруппе с длительностью наркотизации более 1 года и достоверно не отличался от показателя до лечения в подгруппе с длительностью наркотизации до 1 года, что указывает на отсутствие эффекта традиционной терапии на показатели окислительного стресса. Более того, у лиц, имеющих поражение печени, окислительный стресс на фоне традиционной терапии усиливался (табл.2).

При использовании альфа-токоферола в составе оптимизированной терапии отмечалось понижение уровня МДА у пациентов обеих групп, хотя его концентрация не достигала контрольных величин. Обращает внимание, что активность каталазы восстанавливалась до контрольного уровня у всех пациентов и 
статистически не отличалась от уровня контрольной группы. Также примечательно то, что имелись достоверные отличия эффективности оптимизированной терапии с включением антиоксиданта относительно традиционной по показателям МДА, СМП и каталазы.

Как у лиц, длительно злоупотребляющих опиатами, так и у наркоманов со стажем в пределах 1-года оптимизированная терапия с включением антиоксиданта оказывала положительный эффект, более выраженный у пациентов с длительностью наркотизации более 1 года. У них отмечалось более значимое снижение относительно исходного уровня СМП и МДА, что доказывает вклад печени в развитие системного окислительного стресса при опийной наркомании, а также то, что восстановление антиоксидантной мощности организма приводит к купированию окислительного стресса.

Увеличение активности каталазы в результате оптимизированного лечения с применением антиоксиданта привело не только к понижению интенсивности генерации АФК в крови, но и к снижению уровня СМП. Уровень СМП понизился относительно показателя до лечения в 2,4 раза в подгруппе с длительностью наркотизации более 1 года и в 1,9 раза - у лиц с длительностью наркотизации до 1 года.

Изучение периода абстиненции у пациентов, получавших оптимизированное лечение с включением антиоксиданта, показало, что значительно сокращается длительность абстинентного синдрома, снижается патологическое влечение к наркотику, а низкая интенсивность генерации АФК в крови коррелирует с эффективностью терапии. Включение альфа-токоферола в комплекс оптимизированной терапии при зависимости от опиоидов способствует устойчивому и пролонгированному подавлению свободнорадикального окисления в крови, наблюдающемуся сразу после лечения.

\section{Выводы}

1. Интенсивность генерации активных форм кислорода в крови у зависимых от опиоидов возрастает с увеличением длительности наркотизации и сопутствующим поражением печени, проявляясь увеличением малонового диальдегида, среднемолекулярных пептидов и угнетением активности каталазы в 5,0; 5,5 и 3,5 раза относительно контроля соответственно $(\mathrm{p}<0,05)$.

2. С учетом выявленных мембранодеструктивных нарушений в состав патогенетической терапии наркозависимых больных обосновано включение антиоксиданта альфа-токоферола, на фоне лечения которым отмечалось значимое снижение относительно исходного уровня среднемолекулярных пептидов (в 2,4 раза) и малонового диальдегида (в 2,0 раза), сокращение длительности абстинентного синдрома, редукция патологического влечения к наркотику. Включение альфа-токоферола в комплексе оптимизированной терапии зависимости от опиоидов способствует устойчивому и пролонгированному подавлению свободнорадикального окисления в крови, наблюдающемуся сразу после лечения.

\section{References:}

1. Bohan NA (2008) Neyrobiologicheskie problemy izucheniya addiktivnyh rasstroystv (obzor regionalnyh issledovaniy) // N.A.Bohan / Sibirskiy vestnik psihiatrii i narkologii., №1, pp. 59-63.

2. Gabrielyan NI, Levitskiy ER, Dmitriyev AA et al. (1985) Skriningovyi metod opredeleniya "srednih molekul" v biologicheskih jidkostyah: Metodicheskiye recomendatsii. Moscow, 26 p.

3. Zubkova SM, Bah AN (1976) Kolichestvennoye opredeleniye aktivnosti katalazy krovi // S.M.Zubkova, A.N.Bah. / Rukovodstvo k laboratornym zanyatiyam po biologicheskoy himii. Moscow: Meditsina, pp.81-83.

4. Stalnaya ID, Garishvili TG (1977) Metod opredeleniya malonovogo dialdegida s pomoshyu tiobarbiturovoy kisloty/ // I.D.Stalnaya,
T.G.Garishvili / Sovremennye metody v biohimii. Moscow: Meditsina, pp. 66-68.

5. Dudko TN (2011) Sovremennye podhody k reabilitatsii bolnyh $\mathrm{s}$ zavisimostyu ot PAV. // Klinicheskiye i organizatsionnye voprosy narkologii. / Pod red. E.A.Koshkinoy. Moscow: Genius Media, $580 \mathrm{p}$.

6. Tursunhodjaeva LA (2014) Protokol lecheniya opioidnoy zavisimosti. Shifr mejdunarodnoy klassifikacii bolezney - F11.2 / L.A.Tursunhodjaeva, R.P.Korshikova // Tashkent, 7 p.

7. Abdullaeva VK (2016) Clinicalpsychological and pathochemical mechanisms of the opioid addiction of persons with comorbid pathology. ISJ Theoretical \& Applied Science, 01(33):58-63. 
\begin{tabular}{l|lrl|l|ll} 
& ISRA (India) & $=\mathbf{1 . 3 4 4}$ & SIS (USA) & $=\mathbf{0 . 9 1 2}$ & ICV (Poland) & $=\mathbf{6 . 6 3 0}$ \\
Impact Factor: & ISI (Dubai, UAE) $=\mathbf{0 . 8 2 9}$ & PUHL (Russia) $=\mathbf{0 . 1 7 9}$ & PIF (India) & $=\mathbf{1 . 9 4 0}$ \\
& GIF (Australia) & $\mathbf{0 . 5 6 4}$ & ESJI (KZ) & $=\mathbf{1 . 0 4 2}$ & & \\
& JIF & $\mathbf{1 . 5 0 0}$ & SJIF (Morocco) $=\mathbf{2 . 0 3 1}$ & & \\
\hline
\end{tabular}

8. Abdullaeva VK (2012) Clinico-dynamic features of psychopathological disorders at heroin addiction young age. / V.K.Abdullaeva, S.N.Nurkhodjaev // Medical and Health Science Journal, Prague, Czech Republic, Vol.10, pp.52 - 55.

9. Kaplan IY (2000) Somatic and Neurological Complications in Drug Addicts / I.Y. Kaplan, A.A. Kozlov // J. European Psychiatry - Vol. 15, № 2. pp. 436-439.
10. Khalsa JH (2008) Medical Consequences of Drug Abuse and Cooccurring Infections: Research at the National Institute on Drug Abuse / J.H. Khalsa, G. Treisman, E. McCance-Katz, E. Tedaldi // Subst. Abus, Vol. 29, № 3. - pp. 5-16.

11. Koob GF (2006) The neurobiology of addiction / G.F. Koob, M. Le Moal; Eds. G.F. Koob. San Diego: Academic press, 490 p.

12. Lee W (2003) Drug-induced hepatotoxicity // N. Engl. J. Med. - Vol. 349. - pp. 474-485. 